
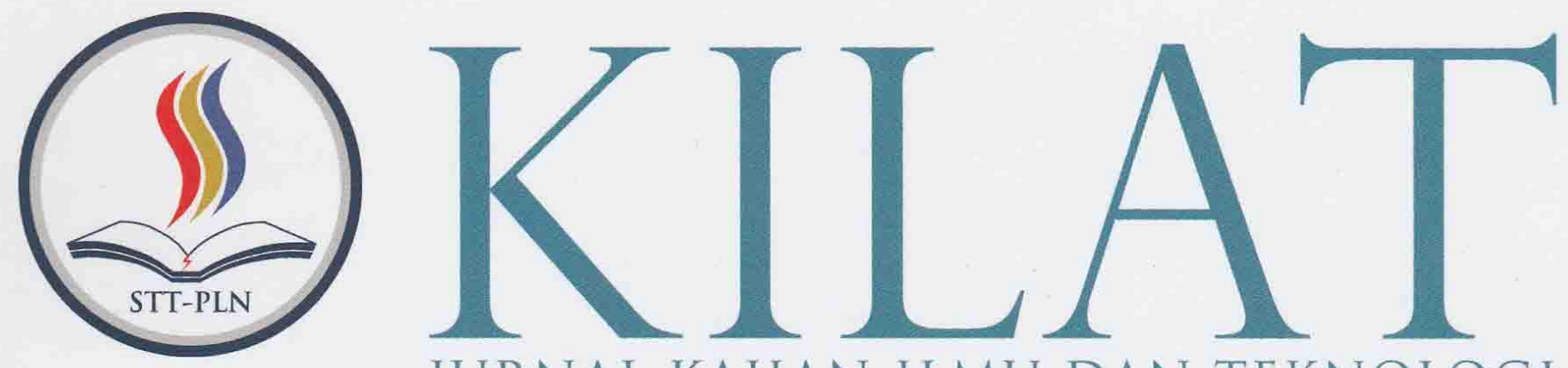
JURNAL KAJIAN ILMU DAN TEKNOLOGI

Dine Tiara Kusuma:

M. Yoga Distra Sudirman: Yessy Fitriani

Emillia; Yuliansyah

Rosida Nur Aziza; Dhzillan Dzhalila

Ranti Hidayawanti

Dewi Arianti Wulandari; Hendra Jatnika; Yudhy S. Purwanto

Rr. Mekar Ageng Kinasti; Endah Lestari; Devita Mayasari

Faisal Piliang

Mauludi Manfaluthy

Pauzi Hasan; Peby Wahyu Purnawan

Rahmi Amir: Baginda Oloan Lubis

Sabar Hanadwiputra; Subandri

Ndaru Ruseno; Satria
PENDEKATAN METODE ALTMAN Z-SCORE DALAM PENENTUAN INSENTIF BONUS PEGAWAI

METODE YURIDIS PENGELOLAAN SAMPAH RUMAH TANGGA DAN SAMPAH SEJENIS DI STT-PLN

METODE KUANTITATIF DENGAN PENDEKATAN KLASIK PADA APLIKASI ANALISIS BUTIR SOAL SEBAGAI MEDIA EVALUASI PENENTUAN SOAL YANG BERKUALITAS

UPAYA TERTIB LISTRIK TERHADAP INSTALATIR KABEL DI DAERAH PADAT PENDUDUK (STUDY KASUS KEC. TAMBORA)

RANCANG BANGUN APLIKASI CLUSTERING DATA MINING MENGGUNAKAN METODE K-MEANS DAN K-MODES

POTENSI PEMANFAATAN LIMBAH PEMBAKARAN BATUBARA (BOTTOM ASH) PADA PLTU SEBAGAI MEDIA TANAM DALAM UPAYA MENGURANGI PENCEMARAN LINGKUNGAN

PEMILIHAN PERANGKAT LUNAK PEMINDAHAN BERKAS DALAM MENINGKATKAN PEMANFAATAN TELEPON PINTAR

PEMANFAATAN RADIASI ENERGI TEGANGAN 150 KV UNTUK LAMPU LED PENERANGAN JALAN

KAJIAN PERBANDINGAN PERFORMANSI ROUTING PROTOCOL RIPNG, OSPFV3 DAN EIGRPVG PADA JARINGAN IPV6

PERANCANGAN PROGRAM PENGELOLAAN DATA KEUANGAN PASIEN RAWAT JALAN BPJS PADA RUMAH SAKIT GRAHA JUANDA BEKASI

ANALISA DAN IMPLEMENTASI VTP DENGAN ETHERCHANNEL TYPE LACP

PENGEMBANGAN RANCANG BANGUN SISTEM KESISWAAN DENGAN MENGGUNAKAN FRAMEWORK MVC

(MODEL VIEW CONTROLLER)

\begin{tabular}{|l|l|l|l|l|l|}
\hline KILAT & VOL.7 & NO.1 & HAL. 1 - 90 & APRIL 2018 & ISSN 2089 - 1245 \\
\hline
\end{tabular}




\title{
PEMANFAATAN RADIASI ENERGI TEGANGAN 150 KV UNTUK LAMPU LED PENERANGAN JALAN
}

\author{
Mauludi Manfaluthy \\ Jurusan Teknik Elektro, Sekolah Tinggi Teknologi Jakarta \\ e-mail: mauludi@gmail.com
}

\begin{abstract}
WHO (World Health Organization) concludes that not much effect is caused by electric field up to $20 \mathrm{kV} / \mathrm{m}$ in humans. WHO standard also mentions that humans will not be affected by the magnetic field under 100 micro tesla and that the electric field will affect the human body with a maximum standard of 5,000 volts per meter. In this study did not discuss about the effect of high voltage radiation SUTT (High Voltage Air Channel) with human health. The research will focus on energy utilization of SUTT radiation. The combination of electric field and magnetic field on SUTT (70-150KV) can generate electromagnetic (EM) and radiation waves, which are expected to be converted to turn on street lights around the location of high voltage areas or into other forms. The design of this prototype works like an antenna in general that captures electromagnetic signals and converts them into AC waves. With a capacitor that can store the potential energy of AC and Schottky diode waves created specifically for low frequency waves, make the current into one direction (DC). From the research results obtained the current generated from the radiation is very small even though the voltage is big enough.
\end{abstract}

Keywords : Radiance Energy, Joule Thief, and LED Module.

\begin{abstract}
Abstrak
WHO (World Heatlh Organization) berkesimpulan bahwa tidak banyak pengaruh yang ditimbulkan oleh medan listrik sampai $20 \mathrm{kV} / \mathrm{m}$ pada manusia. Standar WHO pun menyebutkan bahwa manusia tidak akan terpengaruh oleh medan magnet dibawah 100 micro tesla dan bahwa medan listrik akan berpengaruh pada tubuh manusia dengan standar maksimal 5.000 volt per meter. Pada penelitian ini tidak membahas mengenai pengaruh radiasi tegangan tinggi SUTT (Saluran Udara Tegangan Tinggi) dengan kesehatan manusia. Penelitian akan berfokus pada usaha pemanfaatan radiasi energi SUTT. Kombinasi medan listrik dan medan magnet pada SUTT (70-150KV) dapat menimbulkan gelombang elektromagnetik (EM) sekaligus radiasi, yang diharapkan dapat dikonversi untuk menghidupkan lampu penerangan jalan disekitar lokasi daerah tegangan tinggi atau ke dalam bentuk lainnya. Perancangan prototype ini bekerja seperti antenna pada umumnya yang menangkap signal elektromagnetik dan mengubahnya menjadi gelombang AC. Dengan adanya capasitor yang dapat menyimpan energy potensial gelombang AC dan Schotky diode yang di buat khusus untuk low frequency wave, membuat arus menjadi satu arah (DC). Dari hasil penelitian didapatkan arus yang dihasilkan dari radiasi sangatlah kecil walaupun tegangan cukup besar.
\end{abstract}

Kata Kunci : Radiance Energi, Joule Thief, Modul LED

\section{PENDAHULUAN}

Seiring dengan bertambahnya penduduk, kebutuhan akan pemukiman semakin bertambah. Semua wilayah di kota-kota besar terutama kini dipenuhi dengan pemukiman padat penduduk. Sehingga mau tak mau tiang-tiang saluran udara yang mengalirkan listrik harus dibangun diatas pemukiman warga. Saluran Udara Tegangan Tinggi (SUTT) merupakan saluran tegangan listrik (70$150 \mathrm{KV}$ ) yang berfungsi untuk menyalurkan energi listrik dari pusat-pusat pembangkit yang jaraknya jauh menuju pusat-pusat beban sehingga energi listrik bisa disalurkan secara efisien. Kehadiran SUTT ini memberi banyak manfaat bagi kehidupan. Adanya jalur transmisi ini, listrik lebih aman dan mudah disalurkan dan mampu menyalurkan daya yang besar dengan susut jaringan yang rendah, voltage regulation yang baik serta lebih mudah dalam pengendalian tegangan dan frekuensi.
Namun demikian, ternyata jalur transmisi ini dapat mengakibatkan radiasi yang bisa berpengaruh terhadap kesehatan manusia. Kemungkinan adanya dampak negatif dari SUTT sekarang ini masih dikhawatirkan oleh masyarakat, khususnya yang tinggal di jalur tersebut. Para ahli epidemiologi masih berbeda pendapat bahwa SUTT dapat membangkitkan medan listrik dan medan magnet yang berpengaruh buruk terhadap kesehatan manusia [1]. Sehingga menimbulkan kekhawatiran terhadap masyarakat yang tinggal di jalur SUTT. Tanpa disadari tiang tiang tinggi dan kabel kabel yang melintang di atas pemukiman tersebut di duga menyebabkan radiasi yang berbahaya bagi kesehatan penduduk. Hal ini menimbulkan isu yang beredar di masyarakat yang belum dapat dibuktikan kebenarannya.

Berbagai protes pun datang dari berbagai pihak terutama para penduduk yang bermukim dibawah aliran saluran udara tegangan tinggi 
tersebut. Kebanyakan dari mereka menuntut agar saluran udara tersebut dialihkan ke tempat lain.

Dengan mempertimbangkan, beberapa pendapat dari berbagai badan resmi, seperti dari WHO (World Heatlh Organization) yang berkesimpulan, tidak banyak pengaruh yang ditimbulkan medan listrik $20 \mathrm{kV} / \mathrm{m}-100 \mathrm{KV} / \mathrm{m}$ pada manusia dan tidak mempengaruhi kesehatan hewan percobaan. Standar WHO pun menyebutkan bahwa manusia tidak akan terpengaruh oleh medan magnet dibawah 100 micro tesla dan bahwa medan listrik akan berpengaruh pada tubuh manusia dengan standar maksimal 5.000 volt per meter.

Peraturan Menteri ESDM Republik Indonesia No. 18 Tahun 2015, tentang Ruang bebas dan Jarak bebas minimum pada SUTT, SUTET, SUTTAS untuk penyaluran tenaga listrik [2]. Kombinasi medan listrik dan medan magnet pada SUTT (70-150KV) dapat menimbulkan gelombang elektromagnetik (EM). Keberadaan gelombang EM didasarkan pada hipotesis Maxwell. Hipotesis Maxwell menyatakan bahwa setiap perubahan medan magnet $B$ akan menimbulkan medan listrik $E$ atau sebaliknya. Maka Melalui penelitian ini kami tidak akan membahas mengenai pengaruh radiasi tegangan tinggi khususnya SUTT terhadap kesehatan, namun kebalikannya kami akan meneliti kemungkinan pemanfaatan dari radiasi di bawah SUTT.

Energi sendiri tidak akan habis termakan waktu. Energi selalu ada sepanjang masa. Energi hanya bisa dirubah bentuk dari satu bentuk energi ke bentuk yang lainnya. Ada berbagai macam energi yang dapat kita eksplor dan manfaatkan jumlahnya. Salah satunya adalah energi elektromagnetik yang merupakan bentuk energi murni yang terdapat di angkasa secara bebas, dan bergerak dengan kecepatan cahaya. Kombinasi medan listrik dan medan magnet pada SUTT dapat menimbulkan gelombang elektromagnetik (EM). Keberadaan gelombang EM didasarkan pada hipotesis Maxwell. Hipotesis Maxwell menyatakan bahwa setiap perubahan medan magnet $B$ akan menimbulkan medan listrik $\mathrm{E}$ atau sebaliknya. Suatu medan EM dapat dinyatakan dalam empat vektor medan, yaitu $E=$ intensitas medan listrik $(\mathrm{V} / \mathrm{m}), \mathrm{D}=$ rapat fluks listrik $(\mathrm{C} / \mathrm{m} 2), \mathrm{H}=$ intensitas medan magnet $(\mathrm{A} / \mathrm{m})$ dan $\mathrm{B}=$ rapat fluks magnet $(\mathrm{Wb} / \mathrm{m} 2)$ yang terkait dengan empat persamaan Maxwell [3]. Pemanfaaatan Radiasi Energi untuk lampu penerangan jalan ini, memanfaatkan radiasi elektromagnetik dibawah SUTT. Dimana input dari radias elektromagnetik ini berdasarkan literatur berkisar di angka 0.1 - 3.5 Mikro [1] Dengan range input tersebut diharapkan dapat dikonversi menjadi tegangan untuk menghidupkan lampu penerangan jalan disekitar lokasi tegangan tinggi.

\section{METODELOGI}

Guna mencapai tujuan yang diinginkan, penelitian ini dilakukan sesuai dengan rancangan alur penelitian yang terdapat pada gambar 1 dibawah ini.

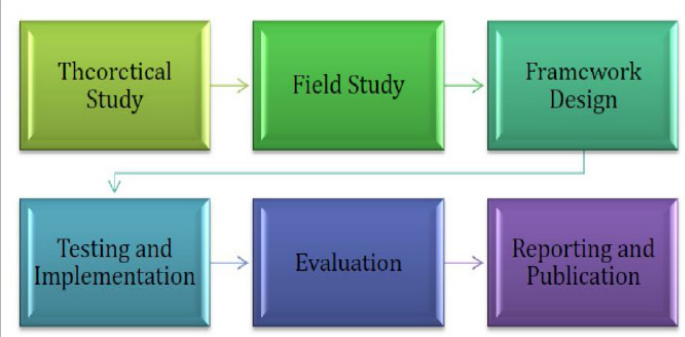

Gambar 1. Alur Penelitian

Penelitian dimulai dari identifikas permasalahan yang ada terkait dengan model alternatif sumber energi bebas dari radiasi saluran tengangan tinggi. Selain itu juga mempelajari literature yang diperlukan, tool maupun modelmodel sumber energi bebas yang ada saat ini yang telah diusulkan oleh peneliti lain sebelumnya. Dilanjutkan dengan perancangan framework dari system yang diusulkan dan pengembangan prototype-nya. Tahapan selanjutnya adalah pengujian terhadap framework yang dibuat dan dilakukan evaluasi untuk memperoleh kesimpulan dari hasil penelitian. Pada tahapan yang terakhir yaitu disusun karya ilmiah hasil penelitian untuk dipublikasikan dalam jurnal karya ilmiah.

\section{HASIL DAN PEMBAHASAN}

Data-data pengukuran hasil penelitian akan dibahas pada sub bab ini. Secara garis besar perancangan prototype adalah seperti pada gambar berikut:

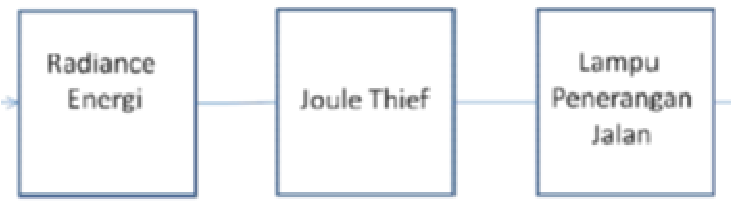

Gambar 2. Blok Diagram Perancangan

Pelaksanaan penelitian dilakukan dibawah SUTT di tiga lokasi berbeda. Gambar-gambar dibawah ini memperlihatkan foto-foto saat penelitian dilakukan.

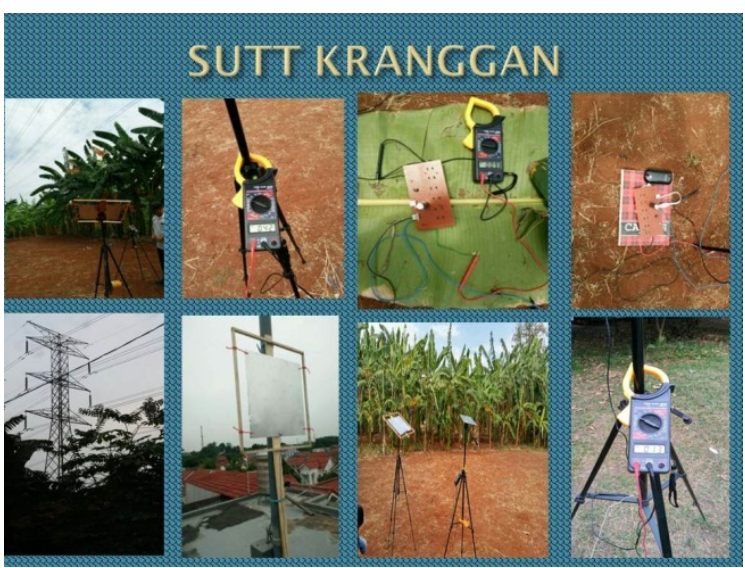




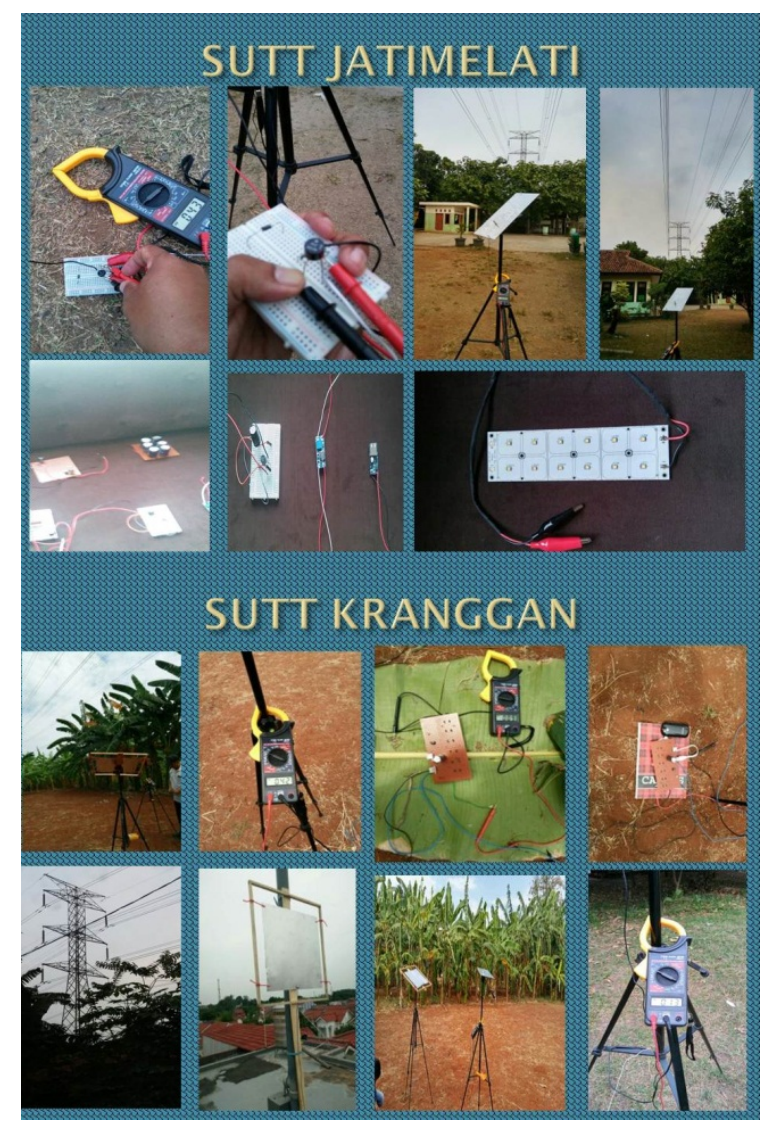

Gambar 3. Foto-foto penelitian di 3 tempat lokasi SUTT

Perancangan ini terdiri dari 3 modul rangkaian yaitu:

1. Radiance Energy

2. Joule Thief

3. Lampu LED Penerangan

Dibawah ini adalah blok diagram dari perancangan pemanfaatan energi untuk lampu penerangan jalan. Adapun penjelasan dari masingmasing module adalah sebagai berikut:

\section{Module Radiance Energy}

Prinsip kerja dari module radiance energy ini adalah berdasar pada prinsip Free Energy Collector dari Tesla. Antenna menangkap energy radiasi bebas/free energy yang selanjutnya akan disimpan dalam suatau kapasitor (C). Dimana muatan listrik secara sementara disimpan sebelum digunakan. Untuk menangkap input radiasi maka akan digunakan Antena. Tepatnya adalah antenna monopole berbentuk plat (berbahan Allumunium). Antena untuk menangkap "listrik" di udara seperti halnya radio menangkap gelombang elekrtomagnetik, Sistem antenna tersebut akan dihubungkan ke ground ( $\mathrm{Gnd}$ ) yang ditancapkan ke dalam tanah.

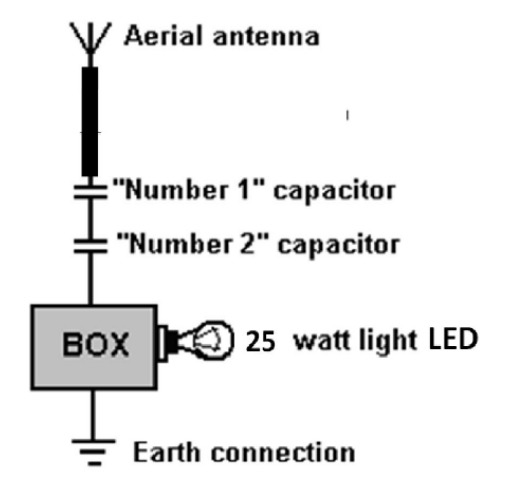

Gambar 4. Model Radiance Energy Tesla

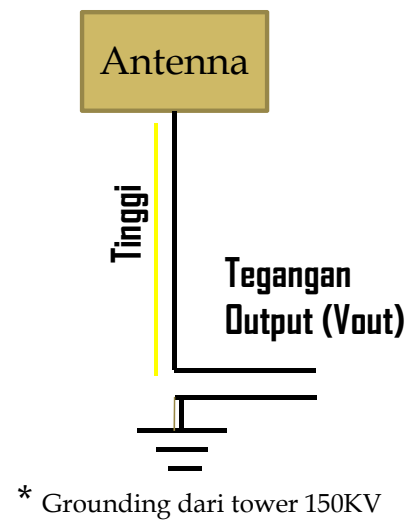

Gambar 5. Prototype Antenna

Berikut ini adalah hasil pengukuran tegangan output (AC) yang didapat dari implementasi antenna diatas:

Tabel 1. Hasil Pengukuran di bawah SUTT

\begin{tabular}{|c|c|c|c|c|}
\hline $\begin{array}{l}\text { Lokasi } \\
\text { SUTT }\end{array}$ & $\begin{array}{l}\text { V Out } \\
\text { (Volt AC) }\end{array}$ & $\begin{array}{l}\text { Type } \\
\text { Antenna }\end{array}$ & Tinggi & $\begin{array}{l}\text { Panjang } \\
\text { Kabel } \\
\text { Antenna }\end{array}$ \\
\hline \multirow{3}{*}{ Jatimelati } & $39-40$ & Plate & $2 \mathrm{~m}$ & $3 \mathrm{~m}$ \\
\hline & $39-40$ & $\begin{array}{c}\text { Parabola } \\
\text { Dish }\end{array}$ & & \\
\hline & $39-40$ & Rod & & \\
\hline \multirow{3}{*}{ Kranggan } & $49-51$ & Plate & $2 \mathrm{~m}$ & $3 \mathrm{~m}$ \\
\hline & $48-50$ & $\begin{array}{c}\text { Parabola } \\
\text { Dish }\end{array}$ & & \\
\hline & $49-51$ & Rod & & \\
\hline \multirow{3}{*}{ Cikunir } & $50-51$ & Plate & $4 \mathrm{~m}$ & $6 \mathrm{~m}$ \\
\hline & $50-52$ & $\begin{array}{c}\text { Parabola } \\
\text { Dish }\end{array}$ & & \\
\hline & $51-54$ & Rod & & \\
\hline
\end{tabular}

Dari tabel di atas dapat di simpulkan tengangan output dari antenna dapat dikatakan stabil dan semakin tinggi antenna tegangan yang dihasilkan tidak berbeda jauh. Selanjutnya output dari antenna di hubungkan dengan module radiance energy (berupa rangkaian penyearah dan penguat), seperti ditunjukan pada gambar di bawah ini. 


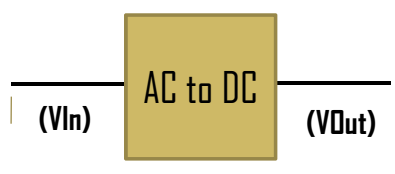

Gambar 6. Blok Diagram Pengubah tegangan AC ke DC

Output tegangan DC yang dihasilkan dapat dilihat pada tabel berikut, dari tabel tersebut arus yang dihasilkan hanya dapat menghidupkan power bank dengan kapasitas rendah (max 2500mAH).

Tabel 2. Tegangan Output yang dihasilkan saat pengukuran di bawah SUTT

\begin{tabular}{|c|c|c|c|}
\hline $\begin{array}{l}\text { V In } \\
\text { (Volt AC) }\end{array}$ & $\begin{array}{l}\text { V Out } \\
\text { (Volt DC) }\end{array}$ & $\begin{array}{l}\text { Beban } \\
\text { Output }\end{array}$ & Keterangan \\
\hline $39-40$ & $15-18$ & $\begin{array}{l}\text { Power } \\
\text { Bank } \\
2600 \\
\text { mAH }\end{array}$ & $\begin{array}{l}\text { Hidup } \\
\text { Sesaat. }\end{array}$ \\
\hline $49-51$ & $17-19$ & $\begin{array}{l}\text { Power } \\
\text { Bank } \\
2600 \\
\text { mAH }\end{array}$ & $\begin{array}{l}\text { Hidup } \\
\text { Sesaat. }\end{array}$ \\
\hline $50-51$ & 21 & $\begin{array}{l}\text { Power } \\
\text { Bank } \\
5600 \mathrm{~m} \\
\text { AH }\end{array}$ & $\begin{array}{l}\text { Hidup, lalu } \\
\text { putus. }\end{array}$ \\
\hline
\end{tabular}

Ide dasar prinsip Tesla adalah menangkap beda potensial listrik di udara (menangkap gelombang elektromagnetik yang berasal dari matahari maupun gelombang kosmik) dengan bumi (ground). Hasil dari prinsip Tesla ini dapat disimpulkan udara lebih bersifat positif $(+)$ dan bumi lebih bersifat negatif (-), sehingga apabila keduanya digabungkan (dihubungkan ke kapasitor ataupun coil / trafo, akan terjadi akumulasi muatan + dan - sehingga terjadilah arus listrik) [4].

\section{Module Joule Thief}

Pada dasarnya rangkaian juole thief ini adalah rangkaian inverter. Ini merupakan rangkaian yang dimodifikasi untuk merubah tegangan DC (Direct Current) atau arus searah menjadi tegangan AC (Alternating Current) atau arus bolak-balik. Dalam rangkaian ini hanya memakai satu transistor saja untuk merubah tegangan DC menjadi tegangan AC. Input dari module radiance energy akan di kondisikan dengan menggunakan dioda untuk disearahkan, lalu output tegangan DC ini akan masuk ke Joule Thief untuk mendapatkan tegangan AC yang lebih standar untuk menyalakan sebuah lampu jalan.

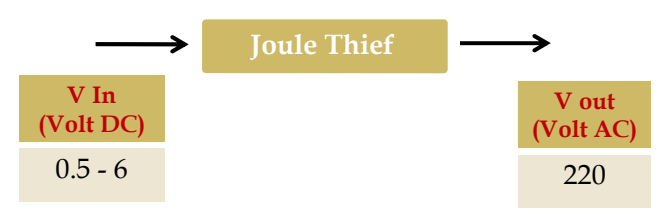

Gambar 7. Blok Diagram Joule Thief

Syarat untuk membuat tegangan $A C$ yakni tegangan output harus berubah menjadi gelombang sinusoidal. Gelombang sinusoidal terjadi dikarenakan adanya perpotongan flux pada kumparan yang diakibatkan oleh tegangan $A C$ itu sendiri [5]. Berikut adalah rangkaian joule thief:

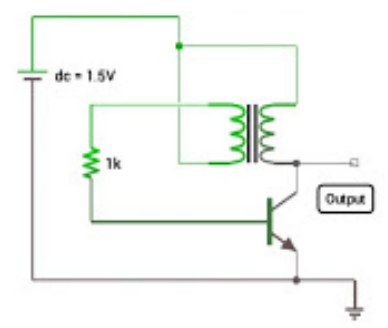

Gambar 8. Rangkaian inverter DC to AC satu transistor

\section{Module Lampu LED}

Modul lampu LED dirancang menggunakan LED dengan komponen berbasis SMD (Surface Mount Device), dimana LED yang digunakan di gerakan pada arus $750 \mathrm{~mA}$.

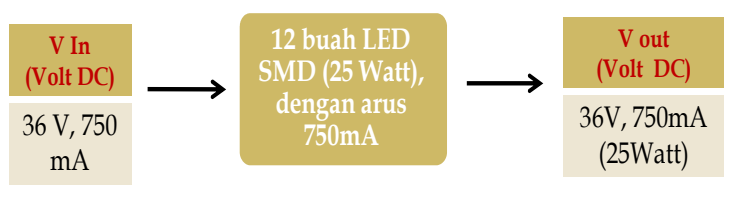

Gambar 9. Blok Diagram prototype Lampu Penerangan LED berbasis SMD.

Tabel dibawah ini adalah, hasil perhitungan dengan mempergunakan tools simulasi LED Samsung. Ada 5 input arus yang disimulasikan dari mulai 0.35 A sampai dengan 1 A (DC). Dengan jumlah lampu LED SMD 12 buah, maka di dapat variasi Watt dari 12.8 - 40. 9 Watt, tentu saja dengan efficacy (Im/watt) yang berbeda-beda. Dari simulasi ini didapatkan efficacy terbaik adalah 114.6 Im/w. Dihasil 20.9 Watt dengan lumen $2397 \mathrm{Im}$.

Tabel 3, Hasil Simulasi lampu LED SMD

\begin{tabular}{|c|c|c|c|c|c|c|c|}
\hline \multicolumn{2}{|c|}{$\begin{array}{l}\text { Filed } \\
\text { (Input) }\end{array}$} & $\begin{array}{c}\text { Current } \\
{[\mathrm{A}]}\end{array}$ & $\begin{array}{l}\text { \# of } \\
\text { LED }\end{array}$ & $\begin{array}{c}\text { EFlux } \\
{[\operatorname{lm}]}\end{array}$ & $\begin{array}{c}\text { EPower } \\
{[\text { W] }}\end{array}$ & $\begin{array}{l}\text { Efficacy } \\
{[\mathrm{Lm} / \mathrm{W}]}\end{array}$ & $\begin{array}{l}\text { Thermal } \\
\text { Guide }\end{array}$ \\
\hline \multicolumn{2}{|c|}{ top>down } & & & - & & & \\
\hline \multirow{6}{*}{ 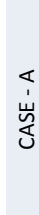 } & 1 & 0.350 & 12 & 1609 & 12.8 & 125.4 & Safe zone \\
\hline & 2 & 0.450 & 12 & 2012 & 16.8 & 119.7 & Safe zone \\
\hline & 3 & 0.550 & 12 & 2397 & 20.9 & 114.6 & Safe zone \\
\hline & 4 & 0.650 & 12 & 2762 & 25.1 & 109.9 & Safe zone \\
\hline & 5 & 0.750 & 12 & 3109 & 29.5 & 105.4 & Safe zone \\
\hline & 6 & 1.000 & 12 & 3887 & 40.9 & 95.0 & Safe zone \\
\hline
\end{tabular}

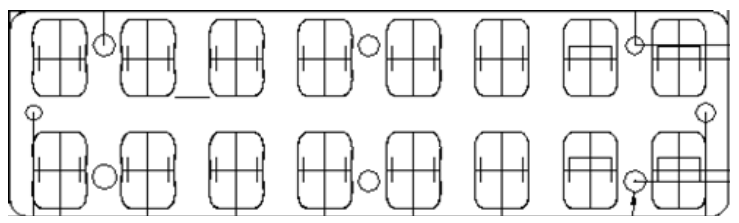

Gambar 10. Model Lensa untuk lampu 12 buah LED 


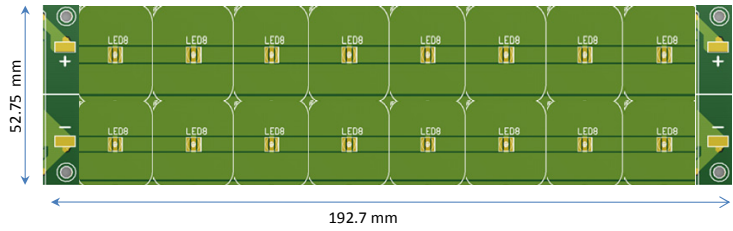

Gambar 11. PCB dengan material alumunium core untuk lampu 12 buah LED

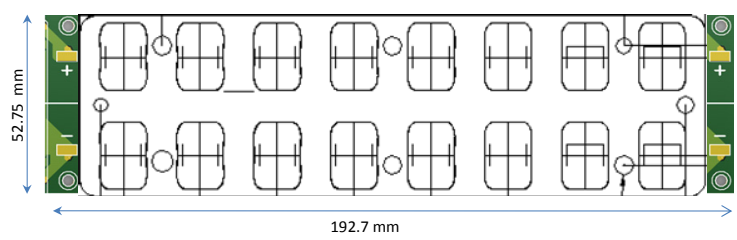

Gambar 12. PCB dan Lensa yang sudah di assembly untuk lampu 12 buah LED

Pemilihan lampu LED didasari karena usia pemakaian lampu LED yang mencapai 50.000 jam serta intensitas terang serta efisiensi yang dihasilkan tinggi. Pada peracangan lampu LED penerangan jalan ini akan dibuat menggunakan sumber tegangan DC. Penggunaan lampu LED selain menghemat daya juga membawa dampak positif lainnya. Lampu LED tidak mengandung merkuri sehingga aman bagi lingkungan. Selain itu dengan menggunakan lampu LED maka akan membantu mengurangi energi fosil yang digunakan dalam proses pembangkitan energi listrik sehingga mengurangi kadar $\mathrm{CO} 2$ di udara [6].

\section{KESIMPULAN} adalah:

Beberapa kesimpulan dari hasil penelitian ini

- Tegangan keluaran antenna berkisar antara 49-51 Volt AC, rata-rata output tegangan sama untuk ketiga lokasi SUTT yang berbeda.

- Modul Joule thief dan Modul Lampu LED sudah berjalan dengan baik, seusai target spesifikasi yang diharapkan.

- Output Antenna dihubungkan dengan adaptor, didapatkan tegangan berkisar 19-21 Volt DC, ketika dihubungkan ke beban/power bank hanya dapat menghidupkan sebentar saja, lalu hilang. Analisa atas hal ini disebabkan oleh arus yang dihasilkan dari radiasi terlalu kecil dalam orde kurang dari $1 \mathrm{~mA}$.

- Tindak lanjut dari peneliatian ini adalah mencari solusi agar dapat dimanfaatkan tegangan keluaran 19-21 Volt DC. Sebagai alternative solusi yaitu dengan menghubungkan output tegangan ke supercapacitor atau baterai, selanjutnya baterai yang akan menghidupkan lampu jalan.

\section{DAFTAR PUSTAKA}

[1] Nanan Tribuana, "Pengukuran Medan Listrik dan Medan Magnet dibawah SUTET 500KV", Elektro Indonesia Nomor 32 tahun. 2000. [On line]

www.elektroindonesia.com/elektro/ener32a.ht $\mathrm{ml}$

[2] Kementerian ESDM, "Peraturan Menteri ESDM Republik Indonesia No. 18 Tahun 2015, tentang Ruang bebas dan Jarak bebas minimum pada SUTT, SUTET, SUTTAS untuk penyaluran tenaga listrik", 2015.

[3] Arif Ismul Hadi, Rida Samdara dan Hesna Nurliana, "Efisiensi tumbuhan dalam meredam Gelombang elektromagnetik (studi kasus di sutt kota bengkulu) ", Jurnal Gradien Vol .8 No.12 Januari 2012: 722-727.

[4] J. Kelly Patrick. (2008), A PracticalGuide to Free-Energy Devices). [Online]. http://www.free-energy-info.com/PJKbook.pdf

[5] Fadhli M.R, "Rancang bangun Inverter $12 \mathrm{~V}$ DC ke $220 \vee$ AC dengan frekuensi $50 \mathrm{~Hz}$ dan Gelombang Keluaran Sinusoidal", Teknik Elektro Fakultas Teknik Universitas Indonesia, Depok, 2010.

[6] Hanum Nayomi, "Peluang Pemanfaatan Lampu LED Sebagai Sumber Penerangan,". Skripsi, Fakultas Teknik Program Studi Teknik Elektro Universitas Indonesia, Depok, 2013. 